\title{
Powder for Suspension Dosage Form
}

National Cancer Institute

\section{Source}

National Cancer Institute. Powder for Suspension Dosage Form. NCI Thesaurus. Code C42975.

A powder that forms a suspension when reconstituted with a liquid solution. 